\title{
PERCEPÇÃO DE ESTUDANTES UNIVERSITÁRIOS DE EDUCAÇÃO FÍSICA SOBRE O ESTÁGIO CURRICULAR SUPERVISIONADO EM TREINAMENTO ESPORTIVO: ESTUDO EM UMA UNIVERSIDADE PÚBLICA BRASILEIRA
}

\author{
PERCEPTION OF UNDERGRADUATE PHYSICAL EDUCATION STUDENTS \\ ABOUT THEIR SUPERVISED PRACTICUM AS SPORTS COACHES: A STUDY \\ CONDUCTED IN A BRAZILIAN PUBLIC UNIVERSITY
}

\section{PERCEPCIÓN DE ESTUDIANTES UNIVERSITARIOS DE EDUCACIÓN FISICA SOBRE LA PRÁCTICA CURRICULAR SUPERVISADA EN ENTRENAMIENTO DEPORTIVO: ESTUDIO EN UNA UNIVERSIDAD PÚBLICA BRASILEÑA}

\author{
Michel Milistetd*, Vinicius Zeilmann Brasil”, William das Neves Salles*, \\ Alexandre Vinicius Bobato Tozetto**, Michel Angillo Saad*
}

Palavras chave: Educação Física. Esportes.

Estágios.

Capacitação profissional.

Keywords: Physical Education.

Sports.

Practicum.

Professional

Training.

Palabras clave: Educación Física. Deportes. Prácticas Curriculares. Capacitación professional.
Resumo: Este estudo descritivo-interpretativo buscou investigar as percepções de estudantes universitários de Educação Física acerca do Estágio Curricular Supervisionado em treinamento esportivo. Entrevistaram-se nove estudantes de uma universidade pública brasileira regularmente matriculados no estágio em treinamento esportivo, e os dados foram analisados por meio da técnica de Análise do Conteúdo. Os estudantes avaliaram positivamente 0 desenvolvimento em ambiente de estágio de conhecimentos adquiridos em disciplinas na universidade e o compartilhamento de experiências, enquanto a ausência de disciplinas que abrangem práticas pedagógicas na área do esporte e falta de acolhimento por determinados locais foram avaliadas negativamente. Os estudantes indicaram, para a melhoria do estágio, a oferta diversificada de áreas para a realização desta atividade, assim como a relação mais próxima da universidade e dos professores orientadores com os locais de estágio e com seus profissionais.

Abstract: This descriptive-interpretative study sought to investigate Physical Education undergraduate students' perceptions about their supervised practicum as sports coaches. We interviewed nine students regularly enrolled in supervised practicum for sports coaches at a Brazilian public university, and data underwent Content Analysis. The students evaluated positively their knowledge acquisition in curricular practicum situations at the university and the experiences shared with colleagues, while they viewed negatively the lack of courses covering pedagogical practices in sport and not being welcome at certain practicum places. As suggestions for improving the practicum, students indicated the need to offer more areas for it as well as closer relations between the university/advisors and places for practicum/their professionals.

Resumen: Este estudio descriptivo-interpretativo buscó investigar las percepciones de estudiantes universitarios de Educación Física sobre la Práctica Curricular Supervisada en entrenamiento deportivo. Fueron entrevistados nueve estudiantes de una universidad pública brasileña regularmente matriculados en la práctica en entrenamiento deportivo, y los datos fueron analizados con la técnica de Análisis de Contenido. Los estudiantes evaluaron positivamente el desarrollo, en el ambiente de la práctica curricular, de conocimientos adquiridos en la universidad y el intercambio de experiencias, mientras que la ausencia de asignaturas que abarcasen prácticas pedagógicas en el área del deporte, así como la falta de acogida en determinados locales fueron aspectos evaluados negativamente. Las sugerencias de los estudiantes para mejorar la práctica supervisada comprenden el ofrecimiento de áreas diversificadas para realizarla, así como la relación más cercana de la universidad y sus profesores con los locales de práctica y sus profesionales.
*Universidade Federal de Santa Catarina. Florianópolis, SC, Brasil. E-mail: michel.milistetd@ufsc.br; vzbrasil@hotmail.com; williamdnsalles@gmail.com; michelangillosaad@gmail.com

**Universidade do Estado de Santa Catarina. Florianópolis, SC, Brasil. E-mail: alexandrebobato@ hotmail.com

Recebido em: 25-06-2017 Aprovado em: 18-08-2018

DOI: https://doi.org/10.22456/1982-8918.74366 (c) (1) (8) Licence cc) Creative Commom 


\section{INTRODUÇÃO}

O reconhecimento da intervenção do treinador esportivo como um processo social, dinâmico, complexo e interacional (JONES; TURNER, 2006) reforça a necessidade dos programas de formação de treinadores priorizarem o desenvolvimento de conhecimentos gerais e específicos para a atuação profissional (conhecimentos profissionais), de habilidades sociais para estabelecer relações em diferentes ambientes (conhecimentos interpessoais) e de habilidades de introspecção e reflexão sobre si mesmo (conhecimentos intrapessoais) (CÔTÉ; GILBERT, 2009).

O contexto universitário tem sido referenciado como uma possibilidade relevante para a formação de treinadores, sobretudo por incentivar interações regulares com os pares e especialistas, além de oportunizar o desenvolvimento de um pensamento crítico-reflexivo (MALLETT; RYNNE; DICKENS, 2013). No Brasil, a intervenção e a formação do profissional atuante no esporte fora do contexto escolar estão vinculadas à área da Educação Física (BRASIL, 1998), sendo que a formação do treinador esportivo é de responsabilidade dos cursos de bacharelado (BRASIL, 2004).

Na tentativa de melhor preparar os futuros profissionais para a intervenção nesta área, a partir das orientações curriculares da Resolução CNE/CES 07/2004, os cursos de formação inicial em Educação Física têm desenvolvido iniciativas como práticas pedagógicas como componente curricular, atividades complementares e Estágios Curriculares Supervisionados (ECS) na área do esporte (MILISTETD et al., 2014).

O ECS, particularmente, possui reconhecida importância por proporcionar: 0 desenvolvimento de conhecimentos adquiridos em outras disciplinas do curso de formação inicial; a observação e diálogo com profissionais mais experientes; e experiências em condições reais de intervenção (BENITES et al., 2012; SILVA JÚNIOR et al., 2016; SOUZA NETO; SARTI; BENITES, 2016). No âmbito da licenciatura, em análise das produções científicas nacionais sobre o tema, Isse e Molina Neto (2016) verificaram um consenso referente à relevância do estágio para a formação de professores e da orientação fornecida aos estagiários durante as atividades do ECS. Além disso, alguns problemas são característicos desta etapa da formação, nomeadamente o restrito diálogo entre universidade e entidade de estágio, a divergência entre os conhecimentos priorizados no curso e as demandas do contexto de intervenção, bem como, a falta de direcionamento das atividades de estágio (ISSE; MOLINA NETO, 2016).

O ECS, no âmbito do bacharelado, parece não se constituir como objeto sistemático de estudo das produções científicas nacionais. Entre as iniciativas nesta área, Anversa et al. (2015) analisaram a percepção de 340 estudantes de cursos de bacharelado Educação Física a respeito da qualidade da formação inicial e do ECS. Os resultados apontam que os graduandos avaliaram o ECS como sendo uma atividade fundamental para a concretização de conhecimentos obtidos no curso, assim como para aproximar-se do mercado de trabalho. Neste sentido, investigações sobre o ECS no âmbito do treinamento esportivo, com universitários norte-americanos (DIEFFENBACH; MURRAY; ZAKRAJSEK, 2011;ZAKRAJSEK; THOMPSON; DIEFFENBACH, 2015) e portugueses (GOMES et al., 2016), igualmente destacam a valorização das situações reais de intervenção profissional e das interações sociais estabelecidas no ambiente de estágio.

Embora seja reconhecida a importância do estágio na formação do profissional de Educação Física, as evidências investigativas sobre este tema parecem não contribuir de modo 
eficaz na estruturação e no desenvolvimento do ECS nesta área profissional, considerando, em especial, a lacuna de estudos sobre o ECS no âmbito do bacharelado. Segundo Anversa et al. (2015), se faz necessária uma análise das estratégias formativas adotadas nos cursos universitários e das demandas de intervenção profissional para fornecer direcionamentos eficazes as situações complementares da formação inicial, dentre eles o ECS, potencializando as experiências profissionais formativas e as relações estabelecidas entre estudantes e a realidade em que estão inseridos.

O objetivo deste estudo, portanto, foi investigar as percepções de estudantes universitários de Educação Física acerca do ECS em treinamento esportivo. Acredita-se que os resultados desta investigação possam contribuir com dados qualitativos acerca das impressões, preocupações e percepções de estagiários (ISSE; MOLINA NETO, 2016). Objetivamente, o propósito é fornecer evidências para reflexão e debate acerca das atividades desenvolvidas no ECS em treinamento esportivo e do tipo de participação dos estudantes neste contexto, para que seja possível fomentar melhorias nesta etapa formativa a partir da percepção dos próprios estagiários.

Destaca-se ainda que um avanço do presente estudo em relação à literatura de suporte (DIEFFENBACH; MURRAY; ZAKRAJSEK, 2011; ANVERSA et al., 2015; ZAKRAJSEK; THOMPSON; DIEFFENBACH, 2015; GOMES et al., 2016) é o fato desta investigação se propor a descrever sugestões para o ECS na perspectiva dos estagiários, o que pode fornecer direcionamentos claros para professores orientadores e profissionais supervisores na condução dos estágios.

\section{PROCEDIMENTOS METODOLÓGICOS}

Realizou-se investigação com caráter descritivo-interpretativo, com abordagem qualitativa (DENZIN; LINCOLN, 2008). O estudo foi aprovado pelo Comitê Nacional de Ética em Pesquisa com Seres Humanos (Plataforma Brasil) sob protocolo n 169.330/2012.

Foram investigados nove estudantes (média de idade de 27,9 $\pm 5,9$ anos) regularmente matriculados na disciplina ECS em Treinamento Esportivo, durante o segundo semestre do ano letivo de 2016. Os estagiários foram contatados pelo primeiro ou pelo terceiro autor por e-mail para verificar a disponibilidade e motivação para participar do estudo. Ambos os autores, no momento da coleta de dados, tinham vínculo de estudantes de doutorado na universidade pública em que ocorreu o estudo e conheciam alguns dos estudantes do ECS por terem tido experiências de ensino anteriores com estes em outras disciplinas do curso.

Com os estudantes que manifestaram interesse, agendaram-se encontros individuais, em local e horário de sua conveniência. No primeiro encontro, foram apresentados os objetivos e procedimentos do estudo para cada um deles, e na sequência foi disponibilizado um Termo de Consentimento Livre e Esclarecido para leitura e assinatura. No segundo encontro, realizouse uma entrevista semiestruturada, na qual os estudantes foram questionados sobre sua participação no estágio. As entrevistas foram realizadas pelo primeiro ou pelo terceiro autor, conforme correspondência das disponibilidades de horário destes e dos entrevistados.

Considerando as temáticas abordadas nos estudos sobre ECS (ISSE; MOLINA NETO, 2016), definiram-se como temas geradores para a entrevista os seguintes aspectos: atividades desenvolvidas no ECS, situações marcantes do ECS, avaliação geral do ECS e sugestões para 
a melhoria do ECS. As entrevistas foram gravadas por meio de gravador digital e os dados obtidos foram armazenados em microcomputador, sendo transcritos literalmente com o auxílio dos programas Windows Media Player e Microsoft Word. A duração média das entrevistas foi de 56,6 $\pm 22,1$ minutos, resultando num volume total de material transcrito de 76 páginas (fonte Times New Roman, 12, espaçamento simples, margens de $2 \mathrm{~cm}$ ).

As transcrições foram encaminhadas pelo primeiro e pelo terceiro autor aos estagiários entrevistados para que estes validassem seu conteúdo e alterassem o que julgassem necessário. Nenhuma alteração foi solicitada. Em seguida, as transcrições revisadas foram inseridas no programa de análise qualitativa NVivo 10. A análise dos dados foi realizada por meio da técnica de Análise de Conteúdo (BARDIN, 2011), seguindo três etapas: 1) Pré-análise, em que foram organizadas as informações transcritas das entrevistas realizadas com cada estagiário; 2) Exploração do material, que consistiu na codificação das transcrições brutas em representações de conteúdo, identificando as unidades de significado em função das categorias de análise; 3) Tratamento dos resultados, em que realizou-se a contagem da frequência das unidades de análise e a organização dos resultados.

A validez interpretativa das categorias de análise e das codificações textuais foi realizada pelo método de peritagem, com auxílio de dois professores universitários com elevada experiência em pesquisa qualitativa e em formação profissional de treinadores esportivos. Para proporcionar o anonimato dos investigados, optou-se por identificá-los no texto por meio de combinação de letras e números (E1,... E9).

\section{RESULTADOS}

\subsection{Atividades desenvolvidas no ECS}

todos os estagiários investigados mencionaram que a participação no estágio, de modo geral, consistiu em auxiliar na condução das atividades desenvolvidas pelo treinador supervisor na entidade receptora (clube). O estagiário E2 destaca que "[...] nós trabalhávamos sempre juntos, eu acompanhava os treinos, ajudava ele na parte técnica, tática e física, geralmente, eu auxiliava em tudo, orientava os atletas e fazia a preparação física também [...]". Já E9 declara que "[... minha função era mais de auxiliar, fiquei responsável só uma vez em que o treinador teve que ir para uma competição e fiquei eu e o supervisor. Mas eu era mesmo auxiliar... ajudava a apitar também [...]". De modo semelhante, E7 recorda de como era sua participação nos treinos sob orientação de seu supervisor:

Na maioria das vezes eu era direcionado para o auxílio nas atividades propostas pelo treinador. O treinador conduzia todo o treino e, por exemplo, ele orientava que o exercício seria passe e arremesso... então ele pedia para eu ficar na atividade e fazer a marcação dos atletas... eu também ficava dando feedback para eles (E7).

O envolvimento de cada estagiário nas atividades teve ênfase em diferentes aspectos do treinamento esportivo e, consequentemente, implicou assumir diferentes papéis e responsabilidades no estágio. No caso de $\mathrm{E} 1$, fica evidente que o trabalho em conjunto com 0 treinador da equipe tinha foco nos aspectos táticos, como ele mesmo afirma: "[...] eu ajudava o treinador na questão do posicionamento, na marcação, em um treino mais tático... eu ajudava no posicionamento e em questões como saída de bola [...]". Já os estagiários E5, E6 e E8 
destacam que a participação nas atividades de treino estava voltada para preparação física dos atletas, conforme o exemplo de E5:

Eu fiz alguns trabalhos à parte com o fisiologista... tirou medidas, isso eu também auxiliei. No futebol tem uma equipe, que é o técnico, o fisiologista, o preparador físico, o preparador de goleiros, então a gente sempre estava naquele meio ali. Mas meu supervisor, que era quem eu auxiliava, era o preparador físico (E5).

Além de estarem envolvidos diretamente na implementação das atividades do treino, alguns estagiários (E4, E5, E6, E8 e E9) mencionaram que auxiliavam seus respectivos treinadores e demais profissionais na realização do planejamento e na avaliação das atividades desenvolvidas. O estagiário E5 recorda que "[...] o meu supervisor era o preparador físico da categoria de base, eu acompanhava as atividades que ele era responsável e auxiliava ele na montagem do planejamento para cada atleta [...]". De modo similar, o estagiário E6 descreve como isso ocorria na sua realidade do estágio:

Eu registrava tudo... o treinador me falava e eu anotava cada palavra para eu saber o que ele estava dizendo, o porquê estava dizendo, porque estava falando naquele momento, então eu anotava tudo, às vezes eu fotografava, filmava. Então todas essas informações davam base para montarmos os treinos seguintes (E6).

\title{
3.2 Situações marcantes do ECS
}

Quando indagados sobre as situações marcantes do estágio, os estagiários E2, E4, E6, E7 e E8 destacaram o fato de eles conseguirem identificar os resultados de sua própria intervenção nas atividades desenvolvidas no decorrer do estágio. Particularmente, E6 reconhece que "[...] o que mais me marcou foi ter percebido a evolução técnica e tática da equipe, eu consegui ver isso nitidamente, ao final do estágio eu percebi a evolução dos atletas, um pouco pelo trabalho que eu fiz e da orientação que o treinador da equipe me deu [...]". No caso de $E 7$, foi por meio de uma experiência em atuar como árbitro de basquetebol que percebeu os impactos de sua intervenção enquanto auxiliar de seu treinador:

\begin{abstract}
Uma oportunidade legal que eu tive foi de arbitrar os jogos dos meninos que eu treinava. No treino, você avisa: 'Não sobe na bandeja desse jeito porque você vai tomar 'toco', não faz arremesso desse jeito porque senão você vai errar ou tomar 'toco". A hora do jogo é a hora da prova, então quando aconteciam no jogo essas coisas que eu tinha falado antes, eu ficava feliz, porque depois no dia do treino eu falava: 'Vocês viram? Eu falei para não fazer isso' (E7).
\end{abstract}

O convívio e as relações estabelecidas com os atletas também foram mencionados por alguns estagiários (E1, E3, E7, E9) como um aspecto marcante. Nas palavras de E1: "[...] a questão de conviver com os atletas durante o treino, de tu saberes que podes brincar com um $\mathrm{e}$ não podes brincar com o outro, toda essa questão de relação com os atletas me marcou muito [...]". Particularmente para E3, a proximidade com os atletas foi tão relevante, para ambas as partes, que o convívio foi além do período em que ele esteve estagiando no clube, como ele mesmo explica:

A convivência com os atletas foi o mais importante. A atenção e o respeito que eles tinham por mim, eles me tratavam como técnico, nunca teve hierarquia, era conversa mútua, troca de experiência. Isso foi tão forte que depois de terminar o estágio eu fui viajar para uma competição com eles e foi uma experiência que vou levar para sempre. Eles disseram que eu era uma pessoa que eles iam sentir muita falta... de vez em quando ainda vou lá visitar (E3). 
O envolvimento em atividades não convencionais do estágio foi destacado pelos estagiários E1, E3 e E9 como situação marcante e que não estava prevista no plano de trabalho deles. E1 acredita que "[...] viajar junto com os atletas e outros profissionais, participar das competições, enfrentar outros clubes, pegar um clube bem forte a gente percebe a organização de um outro clube, isso se torna marcante para a gente [...]". Nas declarações de E9 fica evidente que esta situação foi relevante para que ele se mantivesse engajado nas atividades do estágio, conforme ele mesmo declara:

A melhor parte do estágio foi que eu viajei para uma competição com eles. $\mathrm{Na}$ viagem, a gente dormiu num colégio municipal, todos juntos na sala... A gente fazia tudo para as crianças, ajudava a servir no restaurante, parar para comprar água, lanche... a gente fez tudo. Antes do jogo, a parte de motivação, reunião, foi sensacional, só que isso não estava no script, eu só senti a necessidade disso porque estava muito parado aquele estágio (E9).

Por outro lado, a falta de acolhimento por parte do clube e dos outros profissionais, na percepção de alguns estagiários (E5 e E9), gerou situações marcantes negativas durante o estágio. Sobre esse aspecto, E5 explica que "[...] senti muita falta do professor supervisor comparecer no local do estágio... ficou algo muito informal; eu era um aluno, uma pessoa qualquer, no meio do trabalho de profissionais que já possuem um planejamento... acredito que faltou deixar nós, estagiários, mais à vontade [...]".

\subsection{Avaliação geral do ECS}

Considerando os aspectos que foram avaliados positivamente, destacam-se as situações em que os estagiários tiveram a possibilidade de interagir e trocar experiências com os colegas que igualmente participavam do estágio (E1, E2, E3, E5, E6 e E9). Na percepção de $E 1$, "[...] o que mais contribuiu foram os encontros em aula, porque tu trocas experiências com os colegas que estão estagiando em outros locais [...]". O estagiário E5 destaca o fato de interagir com os colegas, principalmente pela quantidade e diversidade de experiências de cada estudante, como ele mesmo explica:

Os encontros que a gente tinha para trocar algumas experiências foram muito importantes, conversar durante a aula. Eu já tinha um pouco mais de experiência, tinha outro que já trabalhava com o futsal também, então era legal conversar entre a gente, ver o que acontece em outros lugares, para dar dicas para outros que estão começando agora (E5).

As distintas experiências vividas durante o estágio foram aspectos positivos destacados por alguns estagiários (E1, E3, E4, E5, E8 e E10). Nas palavras de E9 "[...] o que mais valeu foi acompanhar na competição, cuidar das crianças, as regras estabelecidas, a metodologia usada, questão de organização, horários, ambientar no ginásio, aquecimento, bagunça de vestiário [...]". A participação no dia a dia de trabalho parece ter possibilitado a alguns deles desenvolver determinadas competências. Como exemplo, E4 destaca ter desenvolvido suas competências comunicativas: "[...] o estágio me ajudou muito a trabalhar com pessoas. Eu era muito tímido para falar em público, para realizar trabalho com mais gente, então ali, como tem vários atletas, com uma faixa etária um pouco menor que a minha, eu consegui destravar, falar em público, ter uma dinâmica melhor [...]". Já o estagiário E8 menciona que a autonomia que teve para desenvolver as atividades do estágio lhe proporcionou perceber seus próprios conhecimentos e competências, como ele mesmo afirma: 
Eu tive a liberdade de fazer aquilo que sabia de melhor, usar meus conhecimentos... claro que tudo repassado para o meu supervisor. Isso foi fundamental, porque no estágio a gente tem que demonstrar tudo aquilo que já aprendeu, então a gente coloca na prática tudo aquilo que tinha na teoria, acaba unindo as duas coisas e sendo de grande valia (E8).

Ainda como aspectos positivos do estágio, os estagiários E1, E3 e E6 reconheceram a importância do suporte oferecido pelo profissional supervisor (treinador, preparador físico), conforme a declaração de E3: "[...] eu aprendi demais em tão pouco tempo! Às vezes tu queres ver um pouquinho mais aquilo ali porque está sendo muito boa a convivência, quer aprender um pouco mais porque não é todo dia que eu tenho um orientador que treina uma seleção [...]".

Referente aos aspectos que foram considerados como dificuldades ou barreiras, destaca-se a pouca contribuição das disciplinas oferecidas no curso para o desenvolvimento das atividades no estágio (E1, E2, E3 e E6). 0 estudante E3 acredita que a principal dificuldade foi a falta de oportunidades para desenvolver os conhecimentos aprendidos em outras disciplinas em suas tarefas no estágio, como ele mesmo afirma:

Acredito que faltou a universidade perceber que a gente chega muito 'cru' no estágio. A teoria não está muito vinculada com a prática, e aí quando tu chega na prática tu 'apanha' muito. A formação que eu tive na universidade não serviu muito para chegar no estágio e lidar com isso, foi lá que eu aprendi mesmo. Acho que a universidade tinha que trabalhar melhor essa forma de teoria vinculada com a prática nos estágios (E3).

Outro aspecto destacado foi a dificuldade de inserção nos locais de realização do estágio (E1 e E8). Sobre este aspecto, E1 destaca que "[...] faltou maior contato da universidade com os locais de estágio, falta supervisão; tem locais que a pessoa ia para lá e ficava só observando e não atuava. Então, precisa ter essa conversa maior, para deixar os estagiários atuarem [...]". Além disso, o tempo de duração do estágio e sua disposição no currículo do curso também foram mencionados como aspectos negativos do estágio (E6 e E8), conforme menciona E6: "[...] acho que o estágio é curto, confronta com outras disciplinas que são importantes. Se alguns dos objetivos no bacharelado são os esportes e o treinamento esportivo, deveria ter alguma forma para ver aqueles que querem realmente [...]".

\subsection{Sugestões para a melhoria do ECS}

Referente às sugestões dos estudantes para a melhoria do estágio, verificou-se um consenso (E2, E4, E6 e E8) a respeito da necessidade de adequar o estágio aos interesses e necessidades dos graduandos. $\mathrm{O}$ estagiário $\mathrm{E} 4$ acredita que "[...] se cada um direcionasse para a área que tem interesse e não para área que sobra ou porque não tem hora disponível, acho que se tornaria um estágio mais dinâmico [...]". E8 compartilha esse mesmo entendimento e adverte que "[...] teve gente que chegou para mim e falou que estava fazendo por fazer, que estava contando as horas para terminar, porque não conseguiu no local que queria [...]". Além de abranger a área de interesse do estagiário, E6 destaca a necessidade de melhorias no papel do professor orientador e da disponibilidade de horários, como ele mesmo afirma:

Acredito que deveriam ter professores mais focados em cada aluno, saber o que realmente está acontecendo com cada um. Acredito que eles devem oferecer mais áreas e mais horários... eu ainda tive sorte de ter um lugar bom com pessoas boas (E6). 
A necessidade de uma relação mais próxima entre a universidade e as entidades de realização do estágio foi mencionada pelos estagiários E5, E6, E7 e E10. Para E6 "[...] é preciso fazer algo mais formal. No local de estágio nem uniforme eu tinha, ninguém sabia quem eu era. Podia ter alguma coisa para a identificação, porque você está ali no meio [...]". Nesse sentido, o estagiário E5 sugere que "[...] antes de começar o estágio, o próprio professor da disciplina poderia apresentar uma ementa para o supervisor de estágio para não deixar o aluno à deriva, responsável por tudo [...]".

Já o estagiário E7 sugere que deveria haver situações envolvendo ambas as entidades (professor orientador e o profissional supervisor) para proporcionar ao estagiário um ambiente de estágio favorável a aprendizagem, como ele mesmo declara:

\footnotetext{
É importante que o aluno seja apresentado na hora que ele vai entrar no estágio, escrever um currículo específico a respeito da vida dele. Essa segunda parte deveria ser cobrada pelo próprio professor da disciplina de estágio. Acredito que se deve reforçar aos treinadores que apresentem os estagiários para que os atletas entendam que aquela pessoa apareceu lá no treino está se capacitando na área, que escolheu aquilo que está fazendo, e que está lá para ajudar, aprender e ensinar (E7).
}

Os estagiários E7 e E8 recomendam uma orientação mais efetiva por parte do professor orientador (universidade) e do profissional supervisor de campo. E8 sugere que "[...] seria interessante fazer uma avaliação mensal com perguntas que o professor mandasse e a gente pudesse responder e, tendo em vista nossas respostas, ele mandasse algumas colocações e estudos para ajudar a gente na prática [...]". Outra sugestão verificada foi a formulação de objetivos claros para a disciplina do estágio, fornecendo maior direcionamento à participação do estagiário. Nas palavras de E9: "[...] é importante visar mais o objetivo do estágio, porque ali eu acompanhava treino, mas não tinha nenhuma finalidade, como uma competição, equipes com calendário esportivo, por exemplo [...]". Além disso, o estagiário E1 sugere que "[...] a disciplina deve trabalhar um pouco mais o que você vai encontrar lá, ter umas aulas para chegar lá com mais segurança, tem a pessoa que vai 'crua' para o estágio, ela vai chegar lá, se deparar com as coisas e não vai conseguir entender direito [...]".

\section{DISCUSSÃO}

A participação dos estagiários parece ter sido direcionada pelo aspecto ou elemento do treinamento no qual estiveram envolvidos. O auxílio ao supervisor nas atividades de planejamento, na condução e avaliação foi de suma importância, sobretudo por estarem, progressivamente, engajados em atividades úteis ao treinamento e sob a orientação de um profissional experiente (supervisor). De fato, a possibilidade de aplicar, no campo prático, os conhecimentos teóricos desenvolvidos ao longo da formação inicial tem sido percebida como uma das principais contribuições do ECS, tanto nos cursos de bacharelado (ANVERSA et al., 2015) quanto da licenciatura (BENITES et al., 2012; ISSE; MOLINA NETO, 2016) em Educação Física.

Em estudo com oito estagiários portugueses no âmbito do treinamento esportivo, Gomes e Mesquita (2015) verificaram que, inicialmente, os estudantes apresentavam participação mais periférica nas atividades de treinamento, bem como nos relacionamentos estabelecidos com os demais profissionais e atletas do clube. Ao longo do estágio eles foram adquirindo a confiança do grupo, desenvolvendo conhecimentos e competências e, assim, maior segurança 
para assumir o papel de treinador esportivo (GOMES; MESQUITA, 2015). As oportunidades de assumir responsabilidades, de se relacionar com atletas/alunos e de resolver problemas reais da intervenção oferecem condições para a incorporação de um habitus ou para a transformação da identidade do profissional em formação, tanto no âmbito do treino esportivo (FONSECA; MESQUITA, 2015) como para atuação na Educação Física Escolar (SOUZA NETO; SARTI; BENITES, 2016).

A possibilidade de identificar os resultados de sua intervenção como treinadores, as relações estabelecidas com treinadores e atletas e a falta de acolhimento pelo clube foram as situações que mais marcaram a participação dos estagiários investigados no presente estudo. A elevada expectativa dos estudantes pelas atividades experienciais na área do treinamento esportivo (DIEFFENBACH; MURRAY; ZAKRAJSEK, 2011; FONSECA; MESQUITA, 2015) parece ser impulsionada pela necessidade de confirmação de sua intervenção no decorrer do ECS. Enquanto o ECS, no contexto escolar, parece ser percebido com um sentimento de negação da prática dos professores nos primeiros contatos pelos estagiários (SOUZA NETO; SARTI; BENITES, 2016), o reconhecimento da utilidade da participação dos estagiários, como verificado no presente estudo, pode determinar a trajetória de desenvolvimento de conhecimentos e de competências profissionais no campo do treinamento esportivo.

Tais situações expressam a necessidade de os estagiários desenvolverem um senso de "pertencimento" ao papel assumido, à equipe de trabalho da qual fazem parte, e também à própria entidade onde realizam o ECS (GOMES; MESQUITA, 2015). De fato, sentir-se útil, capacitado para desempenhar determinada função e reconhecido pelas pessoas com as quais convive são aspectos fundamentais para o engajamento ativo dos estagiários, motivando-os para um envolvimento duradouro em sua área de intervenção e incorporando elementos à sua identidade profissional (BENITES et al., 2012; TORINO; SISSELMAN-BORGIA, 2017).

O compartilhamento de informações com os colegas, as experiências no dia a dia do estágio e a convivência com o supervisor foram aspectos avaliados positivamente pelos estagiários investigados. Segundo Torino e Sisselman-Borgia (2017), à medida que os estudantes acessam as experiências de seus colegas do estágio, eles ampliam o repertório de recursos para a resolução de suas próprias tarefas. Na realidade de estagiários portugueses, Gomes et al. (2016) verificaram que, na troca de experiências entre eles, ficou evidente a negociação de significados e de ações autênticas ligados ao exercício profissional.

Para alguns estagiários, conviver com seu supervisor foi fundamental para construir suas próprias representações do que é ser treinador. A observação, as orientações recebidas e as conversas são algumas das situações do dia a dia do ECS em que o estagiário aprende na relação direta com seu supervisor. No estudo de Gomes e Mesquita (2015), a intervenção dos supervisores no local de estágio foi fundamental para a promoção da aprendizagem colaborativa, sobretudo porque foram evoluindo as dinâmicas interativas com os estagiários e permitindo-Ihes maior autonomia para partilharem experiências e expressarem seus pensamentos e dúvidas. De fato, servir de modelo para os estagiários e incentivar reflexões e discussões profundas, amplas e críticas a respeito da atividade profissional são funções essenciais do supervisor de estágio (BARNEY; ANDERSEN, 2014; DIEFFENBACH; MURRAY; ZAKRAJSEK, 2011).

A pouca contribuição das disciplinas do curso, a inserção no local do estágio e o seu tempo de duração foram avaliados negativamente pelos estagiários investigados no presente 
estudo. De acordo com Anversa et al. (2015), a falta de articulação dos componentes curriculares dos cursos de bacharelado em Educação Física com a realidade das atividades desenvolvidas pelo estudante em ambiente de estágio é um motivo substancial para a ineficiência do estágio nesta área. Segundo Marcon, Graça e Nascimento (2011), as práticas pedagógicas como componente curricular (PPCC) devem oferecer condições adequadas para que os estudantes sejam encorajados a planejar, aplicar e refletir sobre os conhecimentos teóricos adquiridos no contexto acadêmico. Cabe ressaltar ainda que a definição da carga horária total destinada às atividades de ECS e às atividades complementares (não devem exceder $20 \%$ do total do curso, conforme Resolução CNE/CES 07/2009) dificulta a ampliação do período de ECS na área de treinamento esportivo.

Os estudantes investigados sugerem para o ECS, destacadamente, o estabelecimento de objetivos claros a serem alcançados pelos estagiários; maior variedade de campos de atuação; aproximação entre universidade e os locais de estágio; e a participação efetiva do professor orientador. Essas demandas parecem ser essenciais para a participação mais efetiva e significativa dos estudantes nas atividades do estágio. As atividades desenvolvidas devem estar vinculadas às experiências prévias, vocações e interesses dos próprios estagiários por determinados campos de atuação. 0 alinhamento entre a universidade e os locais de estágio pode implicar maior direcionamento das orientações fornecidas pelo orientador (universidade), levando os estudantes a pensar criticamente sobre sua atuação no ECS (ZAKRAJSEK; THOMPSON; DIEFFENBACH, 2015). Por outro lado, essa aproximação pode fazer com que a entidade (local de estágio) melhor acolha os estagiários, proporcione uma participação mais ativa dos estudantes e, ainda, considere a situação de estágio como uma possibilidade de reflexão e aprimoramento de suas próprias atividades e profissionais.

É consenso que, para alcançar os propósitos do ECS, as atividades devem ser planejadas e organizadas a partir de objetivos pedagógicos claros, considerando as experiências prévias dos estudantes e priorizando experiências profissionais significativas. Isto envolve 0 processo complexo de transição do ofício de aluno para o habitus de professor (SOUZA NETO; SARTI; BENITES, 2016) - no caso deste estudo, o habitus de treinador esportivo, implicando na incorporação de elementos culturais de uma determinada atividade profissional pelo estagiário. No ECS de cursos de bacharelado, parece que a delimitação desses elementos se configura de maneira mais dinâmica e variada do que no contexto da licenciatura, sobretudo pela variedade de contextos para intervir, pelos diferentes objetivos das atividades que podem ser desenvolvidas no âmbito esportivo (lazer, saúde, rendimento), bem como pelas entidades às quais elas estão vinculadas (clubes, associações esportivas, projetos sociais, etc.).

\section{CONSIDERAÇÕES FINAIS}

De acordo com as percepções dos estudantes investigados sobre o ECS em treinamento esportivo, pode-se concluir que a participação desses indivíduos no ECS consistiu no auxílio à condução das tarefas de treino sob orientação do treinador responsável, bem como no desenvolvimento de atividades de planejamento e avaliação dos treinamentos. A respeito das situações marcantes mencionadas pelos estagiários, destaca-se a valorização das situações em que eles puderam constatar os resultados de sua própria intervenção nas atividades do estágio, as relações estabelecidas com os atletas, a participação em atividades 
fora do contexto de treinamento, e ainda a falta de acolhimento pelo clube e pelos profissionais no local de estágio.

A percepção dos estagiários para a avaliação geral do ECS evidenciou como aspectos positivos o compartilhamento de experiências com colegas de estágio, a variedade de situações vivenciadas, assim como o suporte fornecido pelo supervisor de estágio. Por outro lado, a dificuldade de inserção nos locais de ECS e a pouca contribuição do curso de bacharelado em Educação Física na preparação para o ECS são lacunas percebidas por esses indivíduos. As sugestões dos estudantes investigados para a melhoria do ECS contemplam melhor adequação do estágio às necessidades e interesses dos estagiários; maior efetividade na intervenção do professor orientador do ECS; proximidade entre as entidades envolvidas e seus respectivos profissionais; e também clareza na delimitação dos objetivos a serem alcançados pelos estudantes na participação nas atividades do ECS.

Uma limitação do presente estudo está no fato de não ter incluído outras fontes para obtenção dos dados, como a realização de entrevistas com professores orientadores e profissionais supervisores do estágio, bem como a utilização dos planejamentos de treino, portfólios e outros documentos elaborados pelos estagiários. Destaca-se ainda que a diferença entre a estrutura curricular do ECS dos universitários investigados e a de outras instituições de ensino superior pode limitar a generalização dos dados obtidos. Sugere-se para estudos futuros, portanto, investigar a participação de estudantes de ECS, no âmbito dos esportes, a partir de uma combinação de procedimentos de entrevista, observação e registro sistemático das atividades dos estudantes universitários de diferentes regiões do Brasil, buscando obter informações detalhadas sobre a participação e as interações estabelecidas no cotidiano de ECS em diversos contextos.

\section{REFERÊNCIAS}

ANVERSA, Ana Luiza et al. O estágio curricular em Educação Física - bacharelado. Kinesis, v. 33, n. 1, p. 24-39, jan.jjun. 2015.

BARDIN, Laurence. Análise de Conteúdo. São Paulo: Edições 70, 2011.

BARNEY, Steve; ANDERSEN, Mark. Mindful supervision in sport and performance psychology: Building the quality of the supervisor-supervisee relationship. In: KNOWLES, Zoe et al. (Ed.).

Reflective Practice in the Sport and Exercise Sciences: Contemporary Issues. Oxon: Routledge, 2014. p.147-59.

BENITES, Larissa Cerignoni et al. Qual o papel do professor-colaborador no contexto do estágio curricular supervisionado na Educação Física? Revista Brasileira de Ciência e Movimento, v. 20, n. 4, p. 13-25, 2012.

BRASIL. Lei no 9.696, de 1 de setembro de 1998. Dispõe sobre a regulamentação da Profissão de Educação Física e cria os respectivos Conselho Federal e Conselhos Regionais de Educação Física. Diário Oficial da União, Brasília, DF, 2 set. 1998. Disponível em: <http://www.planalto.gov.br/ ccivil 03/Leis/L9696.htm>. Acesso em: 21 jan. 2017. 
BRASIL. Conselho Nacional de Educação. Resolução CNE no 07, de 31 de março de 2004. Institui as Diretrizes Curriculares Nacionais para os cursos de graduação em Educação Física, em nível superior de graduação plena. Diário Oficial da União, Brasília, DF, 5 abr. 2004. Seção 1, p. 18.

CÔTÉ, Jean; GILBERT, Wade. An integrative definition of coaching effectiveness and expertise. International Journal of Sports Science \& Coaching, v. 4, n. 3, p. 307-323, 2009.

DENZIN, Norman; LINCOLN, Yvonna. Collecting and interpreting qualitative materials. $3^{\text {rd }}$ ed. Los Angeles: Sage, 2008.

DIEFFENBACH, Kristen; MURRAY, Melissa; ZAKRAJSEK, Rebecca. The coach education internship experience: An exploratory study. International Journal of Coaching Science, v. 5, n. 1, p. 3-25, jan. 2011.

FONSECA, Joana; MESQUITA, Isabel. Desenvolvimento da Identidade Profissional do Treinador Desportivo - Uma área a explorar. In: MESQUITA, Isabel (Org.). Investigação na formação de treinadores: identidade profissional e aprendizagem. Porto: Greca Artes Gráficas, 2015. p. 87-123.

GOMES, Rúben et al. Latent learning in the work place: the placement experiences of studentcoaches. Sport, Education and Society, p. 1-14, 2016. Disponível em: <http:/www.tandfonline.com/ doi/abs/10.1080/13573322.2016.1141287>. Acesso em: 26 jan. 2017.

GOMES, Rúben; MESQUITA, Isabel. As dinâmicas relacionais de treinadores estagiários numa comunidade de prática. In: MESQUITA, Isabel (Org.). Investigação na formação de treinadores: identidade profissional e aprendizagem. Porto: Greca Artes Gráficas, 2015. p. 219-258.

ISSE, Silvane Fensterseifer; MOLINA NETO, Vicente. Estágio supervisionado na formação de professores de Educação Física: produções científicas sobre o tema. Revista da Educação Física/ UEM, v. 27, n. 1, 2016. Disponível em: < http://www.periodicos.uem.br/ojs/index.php/RevEducFis/ article/view/31145>. Acesso em: 26 jan. 2017.

JONES, Robyn; TURNER, Poppy. Teaching coaches to coach holistically: Can problem-based learning (PBL) help? Physical Education and Sport Pedagogy, v. 11, n. 2, p. 181-202, 2006.

MALLETT, Clifford; RYNNE, Steven; DICKENS, Sue. Developing high performance coaching craft through work and study. In: POTRAC, Paul; WADE, Gilbert; DENISON, Jim (Ed.). Routledge handbook of sports coaching. Abingdon: Routledge, 2013. p. 463-475.

MARCON, Daniel; GRAÇA, Amândio; NASCIMENTO, Juarez Vieira do. Critérios para a implementação de práticas pedagógicas na formação inicial em educação física e implicações no conhecimento pedagógico do conteúdo dos futuros professores. Revista Brasileira de Educação Física e Esporte, v. 25, n. 3, p. 497-511, jul./set. 2011.

MILISTETD, Michel et al. Coaching and coach education in Brazil. International Sport Coaching Journal, v. 1, n. 3, p. 165-172, 2014.

SILVA JÚNIOR, Arestides Pereira da et al. Estágio curricular supervisionado na formação de professores em Educação Física: uma análise da legislação a partir da resolução CFE 03/1987.

Pensar a Prática, v. 19, n. 1, p. 1-14, jan./mar. 2016.

SOUZA NETO, Samuel de; SARTI, Flávia Medeiros; BENITES, Larissa Cerignoni. Entre o ofício de aluno e 0 habitus de professor: os desafios do estágio supervisionado no processo de iniciação à docência. Movimento, v. 22, n. 1, p. 311-324, jan./mar. 2016. 
TORINO, Gina; SISSELMAN-BORGIA, Amanda. Homeless Microaggressions: Implications for Education, Research, and Practice. Journal of Ethnic \& Cultural Diversity in Social Work, v. 26, n. 1-2, p. 153-165, 2017.

ZAKRAJSEK, Rebecca; THOMPSON, Melissa; DIEFFENBACH, Kristen. An exploration of the academic coaching education internship. Sports Coaching Review, v. 4, n. 1, p. 24-40, 2015. 
